\title{
Small differences in root distributions allow resource niche partitioning
}

\author{
Andrew Kulmatiski ${ }^{1}$, Karen Beard ${ }^{1}$, Martin Holdrege ${ }^{1}$, and Edmund February ${ }^{2}$ \\ ${ }^{1}$ Utah State University \\ ${ }^{2}$ University of Cape Town
}

May 27, 2020

\begin{abstract}
1. Deep roots have long been thought to allow trees to coexist with shallow-rooted grasses. Due to the difficulties of working belowground, data demonstrating water uptake and niche partitioning are uncommon. 2. We describe tree and grass root distributions using a depth-specific tracer experiment in a subtropical savanna, Kruger National Park, South Africa. The depthspecific tracer experiment was conducted three times during each of two growing seasons. These point-in-time measurements (i.e., tracer-defined root distributions) were then used in a soil water flow model to estimate continuous water uptake by depth and plant growth form (trees and grasses) across the two growing seasons. 3. Most active tree and grass roots were in shallow soils: the mean depth of water uptake was $22 \mathrm{~cm}$ for trees and $17 \mathrm{~cm}$ for grasses. However, slightly deeper rooting distributions provided trees with $5 \%$ more soil water than the grasses in a drier precipitation year, but $13 \%$ less water in a wet year. Small differences in rooting distributions also provided both trees and grasses with depths and times at which each rooting distributions (tree or grass) could extract more soil water than the other (i.e., unique hydrological niches of 4 to $13 \mathrm{~mm}$ water). 4. The effect of rooting distributions has long been inferred. By quantifying the depth and timing of water uptake, this research demonstrated that even though rooting distributions appeared similar, they provided trees and grasses with more total water, access to a unique hydrologic niche, or both. This approach demonstrated how even small differences in rooting distributions can provide plants with resource niches that can contribute to species coexistence.
\end{abstract}

\section{Hosted file}

sabie_water_uptake.docx available at https://authorea.com/users/326764/articles/454538-smalldifferences-in-root-distributions-allow-resource-niche-partitioning 